
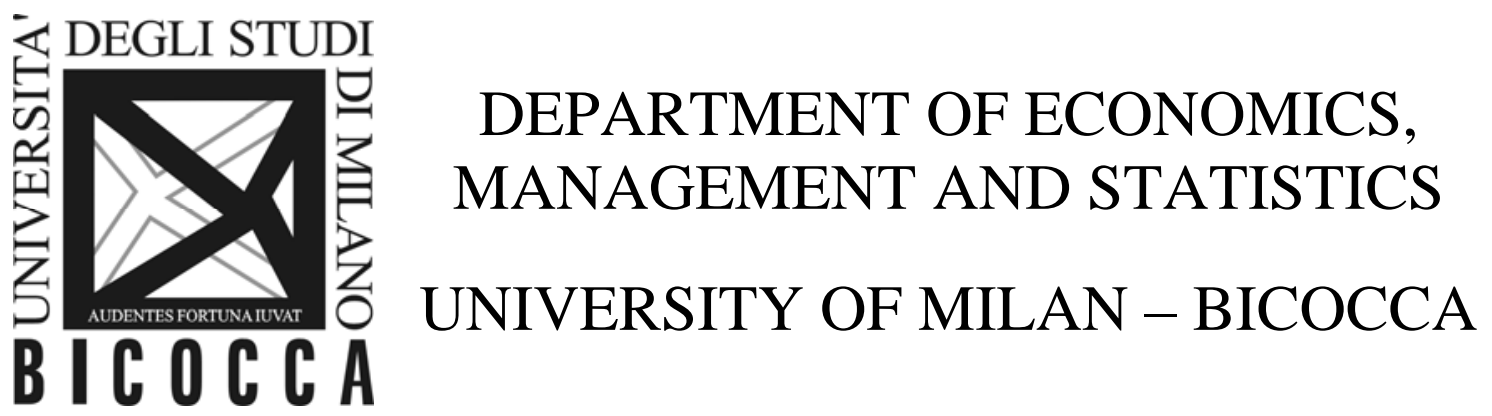

DEMS WORKING PAPER SERIES

Contract Competition between Hierarchies, Managerial Compensation and Imperfectly Correlated Shocks

Michela Cella, Federico Etro

No. 328 - February 2016

Dipartimento di Economia, Metodi Quantitativi e Strategie di Impresa Università degli Studi di Milano - Bicocca http://dems.unimib.it/ 


\title{
Contract Competition Between Hierarchies, Managerial Compensation and Imperfectly Correlated SHOCKS*
}

\author{
Michela Cella ${ }^{\dagger}$ and Federico Etro E $^{\ddagger}$
}

\begin{abstract}
We analyze competition through incentive contracts for managers in duopoly. Privately informed managers exert surplus enhancing effort that generates an externality on the rival. Asymmetric information on imperfectly correlated shocks creates a two-way distortion of efforts under strategic substitutability in effort and a double downward distortion under strategic complementarity in effort. In the first case, as with contracts for R\&D activity or small contractual spillovers for quantity and price competition, increasing the correlation of types reduces the polarization of contracts and the differentials in managerial compensations between efficient and inefficient managers. In the second case, as with large contractual spillovers, the opposite occurs.
\end{abstract}

Keywords: oligopoly, screening, two way distortion, incentives, investments

JEL codes: D21, D82, D86, L13, L22

${ }^{*}$ We are thankful to the Editor Giacomo Corneo, and Patrick Rey, Giacomo Calzolari, Salvatore Piccolo, Elena Manzoni, Giovanna Iannantuoni, seminar participants at CSEF (Naples), participants at SAET 2011 (Faro, Portugal), SfED 2011 (Montreal, Canada) and in particular to two referees for useful comments. Remaining errors are our own.

${ }^{\dagger}$ Corresponding Author. Dept. of Economics, University of Milan- Bicocca. Address: Piazza dell'Ateneo Nuovo 1, Milan (Italy). Email: michela.cella@unimib.it

${ }^{\ddagger}$ Dept. of Economics, University of Venice, Ca’ Foscari, Cannaregio, 30121, Fondamenta S.Giobbe 873, Venice. E-mail: federico.etro@unive.it 


\section{Introduction}

Most of the analysis on principal-agent contracts has been focused on isolated hierarchies where the principal is a monopolist - see Baron and Myerson (1982) or Laffont and Tirole (1986) - but has ignored, until recently, that the interaction between members of a hierarchy often occurs in an environment of competition with other firms organized in similar hierarchies. This means that the contracts internal to a single firm may very well be influenced by those in place in competing firms and that firms do actually compete through the choice of their contracts. The most relevant case concerns the contracts for the top managers, whose payment differentials are often wide (Gabaix and Landier, 2008) and motivated by incentive mechanisms (Jensen and Murphy, 1990; Murphy, 1999; Aggarwal and Samwick, 1999,a) that often interact with analogous mechanisms operating in rival firms (Aggarwal and Samwick, 1999,b; Karuna, 2007). This is particularly relevant in concentrated sectors where a handful of top managers are directly competing against each other and managerial compensations are characterized by strong incentive mechanisms. However, similar interactions emerge also in other crucial contracts adopted by firms, such as the incentive contracts for their researchers engaged in product development or for their marketing managers engaged in demand enhancing activities (advertising, product improvements), often with spillovers on other firms of various type. $^{1}$ All these interactions within hierarchies are typically characterized by problems of asymmetric information and shocks that are only partially correlated across firms, and for these reasons the optimal contract within each hierarchy depends on (and exerts an impact on) the contracts of the rivals.

The aim of this paper is to study the equilibrium of competition in contracts, rather than in quantity or price strategies, in a hidden-information screening model. We will commonly refer to the principal as the firm's owner, to the agent as its manager, and to the contract as determining effort and managerial compensation, but other applications are possible. We interpret hidden information as relative to the productivity of managers within a particular firm in the market. This is typical of specialized top managers in oligopolistic markets, especially for multinationals, and allows us to abstract from competition for the managers and focus on competition between firms through contracts.

We initially present a general model where two firms strategically choose contracts for their own manager with the appropriate incentives to undertake some costly and surplus enhancing effort. Managers of a firm can be of two types, efficient or inefficient, where the

\footnotetext{
${ }^{1}$ Even the relation with external partners, such as exclusive dealers or upstream firms, can be governed by incentive contracts that affect (and are affected by) competition.
} 
difference may reflect variable disutility of effort or variable shocks to the firm-manager productivity. The profits of each firm, however, depend on the contracts of both firms through the effort specified in each contract. Initially, we assume that that the types are independently and identically distributed. We start by considering a scenario with full information where competition in contracts amounts to the choice of effort levels and leads to traditional sources of inefficiency. We then introduce asymmetric information within hierarchies and analyze the equilibrium contracts. In this case, new forms of strategic interactions emerge between the effort-wage contracts chosen by the firms for their managers. In particular, under some regularity conditions for the existence of a unique equilibrium, we show that effort and wage differentials between efficient and inefficient managers are increased when the contracts are strategic substitutes. This is the most common case, as in the presence of contracts on $R \& D$ activity to create new products and other managerial tasks aimed at increasing demand or reducing costs under both quantity and price competition: in all these cases, asymmetric information increases the gap between managerial compensations of efficient and inefficient managers. Instead, when the contracts are strategic complements, as contracts for managerial tasks with large positive spillovers on the rivals, competition is softened by asymmetric information and both types of managers are required lower effort levels compared to the case of symmetric information.

Partial correlation of types, due for instance to relevant aggregate shocks, affects equilibrium contracts in novel ways. In the common case of strategic substitutability, an increase in the correlation of types reduces the polarization of contracts and the differentials in executive compensations. Therefore, a lower correlation of shocks faced by firms increases the comparative advantage of the most productive managers in exerting higher effort and the need to pay them more: in other words, high performance is perceived as due to manager specific merits rather than positive common circumstances, and the equilibrium contracts provide larger bonuses for better managers. Accordingly, it is markets characterized by higher variability in managers' abilities and lower importance of aggregate shocks that will be characterized by higher wage differentials. The main testable prediction is that the variance of managerial compensations and the relevance of incentive mechanisms with high payments for efficient managers should be higher in markets characterized by firm specific shocks and lower in markets characterized by high covariance between shocks of competing firms. However, we also notice that in case of strategic complementarity, for instance when spillovers between firm's investments are large, the opposite outcome emerges: when the correlation of shocks increases managerial compensations become more diversified. 
The rest of the work is organized as follows. Section 2 reviews the related literature. Section 3 presents the general model and the main results in case of uncorrelated types of managers. Section 4 extends the analysis to correlated types. Section 5 contains multiple applications. Section 6 concludes. All proofs are in the Appendix.

\section{Related literature}

Our analysis of contract competition is in the spirit of what Myerson (1982) called "principal equilibrium", for which he analyzed conditions for existence. Most of the subsequent studies, however, have been focused on basic moral hazard problems à la Holmstrom-Milgrom within hierarchies. Aggarwal and Samwick $(1999, b)$ have studied the choice of contracts for managers under price and quantity duopoly assuming that managerial compensations depend on the profits of both firms, which provides a rationale for relative performance evaluation. However, they have not considered heterogeneity between managers with private information as a source of wage differentials. ${ }^{2}$ More recently, Lazear (2015) has examined how competition affects the incentives to delegate sales in the presence of moral hazard, but has not considered strategic interactions.

Few hidden information models have analyzed a setting where duopolists engage in price discrimination, generating problems of common agency within a significantly different context than ours. The most relevant article on screening within an oligopolistic framework is by Martimort (1996), who compares the profitability of exclusive dealing versus a common retailer (a problem of common agency à la Bernheim and Whinston, 1986). To analyze the exclusive dealing case, he develops a model with competition through secret contracts. The main finding is a competing contract effect, that reduces the distortion generated by the standard rent-extraction/efficiency trade-off when goods are substitutes. The contract offered by the rival firm affects the agent's incentive constraints directly, therefore modifying the marginal cost of inducing effort. Instead, in our model the rival firm's contract affects the objective function of the principal directly and modifies the marginal benefit of effort. Moreover Martimort (1996) and subsequent applications by Brainard and Martimort (1996) or Piccolo et al. (2008) assume that private information is perfectly correlated, while we allow for independent or imperfectly correlated types. All these earlier works show that the agency conflict inside the hierarchy is solved in a familiar way, with no distortion at the top and a downward distortion for the inefficient types. Contrary to this, we show that strategic interactions between hierarchies bias the equilibrium contracts in the presence of asymmetric information for

\footnotetext{
${ }^{2}$ The same focus on moral hazard applies in the analysis by Baggs and de Bettignies (2007).
} 
both efficient and inefficient types. Our findings on the increase in effort by efficient types may be reminiscent of the countervailing incentives literature - see Lewis and Sappington (1989), where an agent's incentive to over-report or underreport depend on its own type. However, in our model an agent has always an incentive to over-report his disutility from effort. ${ }^{3}$

In Etro and Cella (2013) we have analyzed contract competition in a specific example with cost reducing activities for a linear Cournot oligopoly with a continuum of (uncorrelated) types of managers. In that example, characterized by strategic substitutability, asymmetric information amplifies the wage differentials between low productivity and high productivity managers, and an increase in the number of firms increases the compensation differentials between (any) two types of managers, which suggests a positive relation between competition and high-powered incentives. We complement those findings showing that the wage differentials increase also when shocks between managers become less correlated for any model characterized by strategic substitutability in contracts, and we study the case of strategic complementarity.

Our work is also related to the theory of superstars, which is typically based on models with perfect competition and full information (Rosen, 1981; Gabaix and Landier, 2008). Introducing imperfect competition and asymmetric information provides an additional rationale for large wage differentials in highly concentrated industries with fierce competition, such as the movie industry, the music industry or the sport industry. Consider sport teams that compete in contracts with new athlets whose productivity within a team is (at least in part) a private information. Each contract sets a compensation and requires a certain effort (say in training, in the competition activity or in other collateral activities). Clearly, the effort of each athlet affects the expected payoff of every team at the competition stage, and it is natural to assume that contracts are strategic substitutes: higher productivity in one team reduces the incentives to invest in productivity in an other team. This situation creates naturally large contractual differentials. What we show is that these differentials should enlarge when the correlation between the productivities of the athlets within their teams is lower.

\section{The model}

Consider two firms (hierarchies), $i$ and $j$, choosing contracts for their managers. A contract between the owner of firm $i$ (principal) and its manager (agent) determines

\footnotetext{
${ }^{3}$ More recently Piccolo and Pagnozzi (2010) have found a two-way distortion in a model of information sharing between competing hierarchies when traded goods are substitutes.
} 
effort $e^{i}$ and the wage $w^{i}$. Given the contracts in place, the profits of firm $i$ are given by:

$$
\pi_{i}=\Pi\left(e^{i}, e^{j}\right)-w^{i},
$$

where $e^{j}$ is the effort required by firm $j$ for its own manager. We assume that the profit function of each firm is symmetric, increasing and non-convex in the effort of its manager, $\Pi_{1}\left(e^{i}, e^{j}\right)>0$ and $\Pi_{11}\left(e^{i}, e^{j}\right) \leq 0$. However, we allow for negative or positive spillovers from the other firm (of course, in the absence of spillovers contract competition has no bite). The sign of the cross derivative $\Pi_{12}\left(e^{i}, e^{j}\right)$ can be negative if more effort from the rival reduces the marginal profitability of effort, or positive if the opposite effect happens: we therefore allow for strategic substitutability between contracts $\left(\Pi_{12}\left(e^{i}, e^{j}\right)<0\right)$ or strategic complementarity $\left(\Pi_{12}\left(e^{i}, e^{j}\right)>0\right)$.

Given a contract $\left(e^{i}, w^{i}\right)$ the utility of the manager of firm $i$ of type $k=1,2$ is:

$$
u_{i}=w^{i}-g\left(\theta_{k}^{i}, e^{i}\right)
$$

where $\theta_{k}^{i}$ parametrizes disutility from effort. This satisfies standard assumptions:

A.1.: The disutility of effort is increasing and convex in effort, i.e. $g_{e}>0$ and $g_{e e} \geq 0$, it is increasing in type, i.e. $g_{\theta}>0$, and such that $g_{e \theta}>0$ (Spence-Mirrlees condition) and $g_{e e \theta}(\theta, e) \geq 0$.

The payoff from the outside option for any manager is normalized to zero. Each manager can be of type $\theta_{1}$ (efficient manager) or of type $\theta_{2}>\theta_{1}$ (inefficient manager), and we will consider both the cases of uncorrelated shocks and correlated shocks. The total surplus created in hierarchy $i$ with a manager of type $\theta_{k}^{i}$ is:

$$
S^{i}=\Pi\left(e^{i}, e^{j}\right)-g\left(\theta_{k}^{i}, e^{i}\right),
$$

and the aggregate surplus for the two hierarchies is:

$$
S=\Pi\left(e^{i}, e^{j}\right)+\Pi\left(e^{j}, e^{i}\right)-g\left(\theta_{k}^{i}, e^{i}\right)-g\left(\theta_{k}^{j}, e^{j}\right) .
$$

Its maximization under full information defines the first best effort levels $e_{i j}^{F B}$ when the manager of firm $i$ is of type $\theta_{i}$ and the manager of firm $j$ is of type $\theta_{j}$. These first best contracts solve four optimality conditions expressed as follows: ${ }^{4}$

$$
\Pi_{1}\left(e_{i j}^{F B}, e e_{i j}^{F B}\right)+\Pi_{2}\left(e_{i j}^{F B}, e_{i j}^{F B}\right)=g_{e}\left(\theta_{i}, e_{i j}^{F B}\right),
$$

\footnotetext{
${ }^{4}$ In what follows we assume that the appropriate second order conditions are satisfied.
} 
and the surplus can be allocated across firms' owners and managers through the choice of wages $w^{i}$ and $w^{j}$ depending on the allocation of the bargaining power within hierarchies.

We will repeatedly illustrate our results with two examples of this general model. The first is based on a direct impact of contracts on profitability, and the second on a two stage competition where contracts are chosen in the first stage.

Example 1: Contract competition in R\&D Our simplest example is a model of competition for the market. Consider firms that invest to innovate and create a new product whose value is normalized to unity. In this case we can think of the agents as research teams that spend effort or resources to come up with a new (patentable) product and conquer its market. Effort determines the probability of success (innovation) as $e^{i} \in[0,1]$ for firm $i$, and the disutility of effort is assumed quadratic in the probability of success $g(\theta, e)=\theta e^{2} / 2$ where we assume $\theta>2$. The probability of establishing a monopoly in the new market is $e^{i}\left(1-e^{j}\right)$, that is the probability that $i$ innovates and $j$ does not; we assume that both firms obtain zero net value if they both innovate (which happens with probability $e^{i} e^{j}$ ) because in this case they are engaged in a price war that dissipates all profits.

Given two contracts $\left(e^{i}, w^{i}\right)$ and $\left(e^{j}, w^{j}\right)$, firm $i$ obtains the expected gross profits:

$$
\Pi\left(e^{i}, e^{j}\right)=e^{i}\left(1-e^{j}\right)
$$

with $\Pi_{12}\left(e^{i}, e^{j}\right)=-1$, which implies strategic substitutability. The total surplus created in hierarchy $i$ is:

$$
S^{i}=e^{i}\left(1-e^{j}\right)-\theta_{k}^{i} \frac{\left(e^{i}\right)^{2}}{2},
$$

and it can be easily verified that the first best contracts specify the effort levels $e_{i j}^{F B}=$ $\frac{\theta_{j}-2}{\theta_{i} \theta_{j}-4}$ for $i, j=1,2$. This will represent our workhorse example of a model with strategic substitutability in contracts.

Example 2: Two-stage competition with spillovers We now consider managers engaged in a demand-enhancing activity, say advertising, aimed at increasing the willingness to pay for their products (or, equivalently a cost-reducing activity, say R\&D). This pursuit is often characterized by spillovers: when a firm spends resources to advertise a good or improve its technology, it may increase the demand for its own product (or reduce its cost), but may also induce positive spillover on the demand of susbstitute goods (or on the cost function of the rivals). 
Consider a firm $i$ producing quantity $x_{i}$ with profits:

$$
\pi^{i}=\left(a-x_{i}-x_{j}+\sqrt{e^{i}}+b \sqrt{e^{j}}-c\right) x_{i}-w^{i},
$$

where $a$ parametrizes the intensity of demand and $c$ the marginal cost, while $e_{i}$ and $e_{j}$ represent the investment in advertising (cost reduction) and $b>0$ represents the size of the spillovers on the rival. When $b=0$ the investment of a firm does not affect the profits of the other firm, and when $b=1$ it affects the profits of both firms without distinction.

At the second stage, once contracts are public, firms compete in quantities. The reaction function of firm $i$ is $x_{i}=\left(a+\sqrt{e^{i}}+b \sqrt{e^{j}}-x_{j}-c\right) / 3$. The production of a firm is decreasing in the production of the rival because of strategic substitutability between output strategies, but it is also increasing in the effort of the rival, because this increases the price of both firms. This suggests that advertising by one firm exerts two effects on the final output of the rival: the direct one is positive, due to the demand enhancing role of ads, and the indirect one is negative, due to the expansion of the output of the rival. Let us solve for the Cournot equilibrium quantities:

$$
x_{i}=\frac{a-c}{3}+\frac{(2-b) \sqrt{e^{i}}+(2 b-1) \sqrt{e^{j}}}{3} \text { for } i, j=1,2 .
$$

It is now clear that with small spillovers $(b<1 / 2)$ the advertising activity reduces the production of the rival, but with large spillovers $(b>1 / 2)$ the advertising activity increases the output of the rival. We can finally derive the gross profits as:

$$
\Pi\left(e^{i}, e^{j}\right)=\left[\frac{1}{3}\left(a-c+(2-b) \sqrt{e^{i}}+(2 b-1) \sqrt{e^{j}}\right)\right]^{2} .
$$

This expression is increasing or decreasing in the ads of the rival if respectively $b>1 / 2$ or $b<1 / 2$. More importantly, the impact of advertising on the marginal profitability of a rival can be derived as follows $\Pi_{12}\left(e^{i}, e^{j}\right)=(2-b)(2 b-1) / 6 \sqrt{e^{i} e^{j}}$, which shows that we may have either strategic substitutability, when $b<1 / 2$, or strategic complementarity, when $b>1 / 2$.

In applications that follow, we will focus on the case of large spillovers, in particular with $b=1$. Therefore profits will be:

$$
\Pi\left(e^{i}, e^{j}\right)=\left(\frac{a-c+\sqrt{e^{i}}+\sqrt{e^{j}}}{3}\right)^{2},
$$


with $\Pi_{12}\left(e^{i}, e^{j}\right)=1 / 6 \sqrt{e^{i} e^{j}}>0$. We will adopt a linear disutility of effort, $g(\theta, e)=\theta e$, with $\theta>4 / 9$. Total surplus within hierarchy $i$ with manager of type $k$ will read as:

$$
S^{i}=\frac{\left(a-c+\sqrt{e^{i}}+\sqrt{e^{j}}\right)^{2}}{9}-\theta_{k}^{i} e^{i} .
$$

The first best effort levels can be derived as $\sqrt{e_{i j}^{F B}}=\frac{2(a-c)}{9 \theta_{i}-2\left(1+\theta_{i} / \theta_{j}\right)}$ for managers of types $\theta_{i}, \theta_{j}$ with $i, j=1,2$. This will represent our workhorse example of a model with strategic complementarity in contracts.

\subsection{Contract competition with full information}

As a benchmark for our future analysis of contract competition, let us consider the case in which managers' types are common knowledge, so that there is full information within hierarchies and also across hierarchies. Given the types $\theta_{k}^{i}$ and $\theta_{k}^{j}$ for the two managers, each firm creates the surplus:

$$
S^{i}=\Pi\left(e^{i}, e^{j}\right)-g\left(\theta_{k}^{i}, e^{i}\right)
$$

The full information Nash equilibrium requires that contracts are decided within each hierarchy independently and taking as given the contracts of the other firm. Given full information, each hierarchy can choose its effort $e^{i}$ to maximize its own surplus and allocate the latter between principal and agent through the wage $w^{i}$. This allows one to easily derive the equilibrium effort levels defined as $e_{i j}$ when one manager is of type $i$ and the other of type $j$. The equilibrium is summarized in the following:

Lemma 1. Contract competition with full information implies that, in case of managers of the same type, the equilibrium effort levels satisfy:

$$
\Pi_{1}\left(e_{11}, e_{11}\right)=g_{e}\left(\theta_{1}, e_{11}\right) \quad \text { or } \quad \Pi_{1}\left(e_{22}, e_{22}\right)=g_{e}\left(\theta_{2}, e_{22}\right),
$$

and, in case of managers of different types, the equilibrium effort levels satisfy the system:

$$
\Pi_{1}\left(e_{12}, e_{21}\right)=g_{e}\left(\theta_{1}, e_{12}\right) \quad \text { and } \quad \Pi_{1}\left(e_{21}, e_{12}\right)=g_{e}\left(\theta_{2}, e_{21}\right) .
$$

All these equilibrium effort levels are inefficient because they are chosen without taking into account the externality that each firm exerts on the other firm through its 
effort. In the example of competition for the market it can be easily verified that:

$$
e_{12}=\frac{\theta_{2}-1}{\theta_{1} \theta_{2}-1}>e_{11}=\frac{1}{\theta_{1}+1}>e_{22}=\frac{1}{\theta_{2}+1}>e_{21}=\frac{\theta_{1}-1}{\theta_{1} \theta_{2}-1} .
$$

In the example of two-stage competition with large demand spillovers we have:

$$
\sqrt{e_{11}}=\frac{a-c}{9 \theta_{1}-2}>\sqrt{e_{12}}=\frac{a-c}{9 \theta_{1}-1-\frac{\theta_{1}}{\theta_{2}}}>\sqrt{e_{21}}=\frac{a-c}{9 \theta_{2}-1-\frac{\theta_{2}}{\theta_{1}}}>\sqrt{e_{22}}=\frac{a-c}{9 \theta_{2}-2} .
$$

In both cases we have $e_{i j}<e_{i j}^{F B}$ for any $i, j .{ }^{5}$ This is a traditional inefficiency: the first best corresponds to collusion in contracts between firms to maximize their joint profits, and Nash competition in contracts leads to lower total profits. The nature of the strategic interaction is analogous to traditional forms of competition in prices or quantities under full information, because only one aspect of the contracts (effort) is the relevant strategic variable.

\subsection{Contract competition with uncertainty}

We now introduce uncertain information across hierarchies. We start by assuming that firms are affected by independent shocks, in the sense that the types of managers are independently distributed: each manager can be of type $\theta_{1}$ with probability $\lambda$ or type $\theta_{2}>\theta_{1}$ with probability $1-\lambda$.

At the contract stage, each firm knows the type of its own manager but not that of the other firm, and can condition its contract only on the former. In other words, there is uncertainty on the type of the other firm's manager, but there is no asymmetric information within each hierarchy in this setup. Contracts are chosen simultaneously taking as given those offered by the other firm and we look for a Bayesian-Nash equilibrium in contracts. Notice that the contract offers are necessarily incomplete in the sense that one firm cannot condition its own contract on the type of the other firm's manager. ${ }^{6}$ As a consequence only two different contracts emerge in a symmetric equilibrium, one for an efficient manager and one for an inefficient manager.

The optimal contract $\left(e_{k}^{i}, w_{k}^{i}\right)$ for a firm $i$ with a manager of type $k$ maximizes its

\footnotetext{
${ }^{5}$ As is well known, strategic delegation can be used by each firm to affect the equilibrium outcomes, but we will not focus on this issue.

${ }^{6}$ This contracting limitation may be due to problems of verifiability on the other firm's variables for lack of auditing rights and abilities - see Brainard and Martimort (1996).
} 
expected surplus:

$$
\max _{\left(e_{k}^{i}, w_{k}^{i}\right)} E\left(S_{k}^{i}\right)=\lambda \Pi\left(e_{k}^{i}, e_{1}^{j}\right)+(1-\lambda) \Pi\left(e_{k}^{i}, e_{2}^{j}\right)-g\left(\theta_{k}, e_{k}^{i}\right) \quad k=1,2
$$

and the optimality conditions are:

$$
\lambda \Pi_{1}\left(e_{k}^{i}, e_{1}^{j}\right)+(1-\lambda) \Pi_{1}\left(e_{k}^{i}, e_{2}^{j}\right)=g_{e}\left(\theta_{k}, e_{k}^{i}\right) \quad \text { for } k=1,2,
$$

which, for given effort levels of the rival firm (i.e. given $e_{1}^{j}$ and $e_{2}^{j}$ ), provide the optimal effort levels $e_{1}^{i}$ and $e_{2}^{i}$. Since we are looking for a symmetric equilibrium we set $e_{k}^{i}=$ $e_{k}^{j} \equiv e_{k}^{*}$ and obtain the following result:

Proposition 1 Under Assumption A.1, the equilibrium effort levels of contract competition with full information within hierarchies and uncertainty on the rival type must satisfy:

$$
\begin{aligned}
& \lambda \Pi_{1}\left(e_{1}^{*}, e_{1}^{*}\right)+(1-\lambda) \Pi_{1}\left(e_{1}^{*}, e_{2}^{*}\right)=g_{e}\left(\theta_{1}, e_{1}^{*}\right) \\
& \lambda \Pi_{1}\left(e_{2}^{*}, e_{1}^{*}\right)+(1-\lambda) \Pi_{1}\left(e_{2}^{*}, e_{2}^{*}\right)=g_{e}\left(\theta_{2}, e_{2}^{*}\right)
\end{aligned}
$$

with $e_{1}^{*}>e_{2}^{*}$.

It is important to remark that the two conditions (17) and (18) are not two reaction functions, but they are two equilibrium relations that link the effort levels required from efficient and inefficient managers. Of course, comparing (17) and (18) in Proposition 1 with (13) and (14) in Lemma 1 shows that for $\lambda \rightarrow 0$ we have $e_{2}^{*} \rightarrow e_{22}$ and for $\lambda \rightarrow 1$ we have $e_{1}^{*} \rightarrow e_{11}$. However, in general, uncertainty about the other firm's manager type influences the optimal effort of a firm because it affects its marginal benefit of effort, and the final impact depends on whether the profit function exhibits strategic substitutability or complementarity in contracts.

The equilibrium condition (17) can be solved for the equilibrium effort of the efficient managers as a function of the equilibrium effort of the inefficient ones:

$$
e_{1}^{*}=f^{*}\left(e_{2}^{*}, \theta_{1}\right)
$$

The slope of this relation in the space $\left(e_{2}^{*}, e_{1}^{*}\right)$ is:

$$
f_{e}^{*}\left(e_{2}^{*}, \theta_{1}\right)=\frac{(1-\lambda) \Pi_{12}\left(e_{1}^{*}, e_{2}^{*}\right)}{g_{e e}\left(\theta_{1}, e_{1}^{*}\right)-(1-\lambda) \Pi_{11}\left(e_{1}^{*}, e_{2}^{*}\right)-\lambda\left[\Pi_{11}\left(e_{1}^{*}, e_{1}^{*}\right)+\Pi_{12}\left(e_{1}^{*}, e_{1}^{*}\right)\right]},
$$


whose sign depends on the numerator once we assume that the denominator is positive. ${ }^{7}$ The equilibrium condition (18) can be solved for an analogous equilibrium relation:

$$
e_{1}^{*}=h^{*}\left(e_{2}^{*}, \theta_{2}\right)
$$

with slope:

$$
h_{e}^{*}\left(e_{2}^{*}, \theta_{2}\right)=\frac{g_{e e}\left(\theta_{2}, e_{2}^{*}\right)-\lambda \Pi_{11}\left(e_{2}^{*}, e_{1}^{*}\right)-(1-\lambda)\left[\Pi_{11}\left(e_{2}^{*}, e_{2}^{*}\right)+\Pi_{12}\left(e_{2}^{*}, e_{2}^{*}\right)\right]}{\lambda \Pi_{12}\left(e_{2}^{*}, e_{1}^{*}\right)},
$$

which has the same sign of the denominator. Restrictions on these slopes are necessary for the existence of a unique interior equilibrium. A sufficient condition for this is the following:

$$
\left|h_{e}^{*}(e, \theta)\right|>\left|f_{e}^{*}(e, \theta)\right|
$$

In the space $\left(e_{2}^{*}, e_{1}^{*}\right)$ this implies that the function $h^{*}\left(e_{2}^{*}, \theta_{2}\right)$ crosses $f^{*}\left(e_{2}^{*}, \theta_{1}\right)$ once and from above under strategic substitutability, while the function $h^{*}\left(e_{2}^{*}, \theta_{2}\right)$ crosses $f\left(e_{2}^{*}, \theta_{1}\right)$ once and from below under strategic complementarity. A Bayesian Nash equilibrium in contracts must be at the unique crossing of the two relations. As before, wages $w_{k}^{i}$ and $w_{k}^{j}$ can be chosen within each hierarchy in function of the bargaining power of principals and managers. As long as there is full information within hierarchies, effort remains the relevant variable of the contracts and the division of surplus within hierarchies does not affect its total.

Example 1: Contract competition in $\mathbf{R} \& \mathbf{D}$ Let us consider our example where two firms are engaged in contract competition for the conquest of a new market. The expected surplus for firm $i$ with manager of type $\theta_{k}$ is:

$$
E\left(S_{k}^{i}\right)=\lambda e_{k}^{i}\left(1-e_{1}^{j}\right)+(1-\lambda) e_{k}^{i}\left(1-e_{2}^{j}\right)-\frac{\theta_{k}\left(e_{k}^{i}\right)^{2}}{2} .
$$

The two equilibrium conditions under symmetry can be derived as two linearly decreasing relations:

$$
\begin{aligned}
& f^{*}\left(e_{2}^{*}, \theta_{1}\right)=\frac{\lambda+(1-\lambda)\left(1-e_{2}^{*}\right)}{\lambda+\theta_{1}}, \\
& h^{*}\left(e_{2}^{*}, \theta_{2}\right)=\frac{1-e_{2}^{*}\left(1-\lambda+\theta_{2}\right)}{\lambda},
\end{aligned}
$$

\footnotetext{
${ }^{7}$ The denominator is always positive in case of strategic substitutability. We assume $\Pi_{12}\left(e_{1}^{*}, e_{1}^{*}\right)<$ $g_{e e}\left(\theta_{1}, e_{1}^{*}\right) / \lambda-(1 / \lambda-1) \Pi_{11}\left(e_{1}^{*}, e_{2}^{*}\right)-\Pi_{11}\left(e_{1}^{*}, e_{1}^{*}\right)$ in case of strategic complementarity. This is easily satisfied in our example.
} 
with intercepts $h^{*}\left(0, \theta_{2}\right)=1 / \lambda>f^{*}\left(0, \theta_{1}\right)=1 /\left(\lambda+\theta_{1}\right)$ and slopes:

$$
\left|h_{e}^{*}(e, \theta)\right|=\frac{1-\lambda+\theta_{2}}{\lambda}>\frac{1-\lambda}{\lambda+\theta_{1}}=\left|f_{e}^{*}(e, \theta)\right|,
$$

satisfying the condition (21). Accordingly we have a unique equilibrium, whose closed form solutions for the effort levels are:

$$
e_{1}^{*}=\frac{\theta_{2}}{\theta_{1} \theta_{2}+(1-\lambda) \theta_{1}+\lambda \theta_{2}}>e_{2}^{*}=\frac{\theta_{1}}{\theta_{1} \theta_{2}+(1-\lambda) \theta_{1}+\lambda \theta_{2}},
$$

as shown in Figure 1. Notice that both effort levels decrease in the probability of efficiency $\lambda$ and the high (low) effort increases (decreases) with the gap between types.

Example 2: Two-stage competition with large spillovers To verify what happens under strategic complementarity, let us consider our example with two-stage competition and large spillovers. Using (11), the expected surplus for firm $i$ with manager of type $\theta_{k}$ is:

$$
E\left(S_{k}^{i}\right)=\lambda \frac{\left(a-c+\sqrt{e_{k}^{i}}+\sqrt{e_{1}^{j}}\right)^{2}}{9}+(1-\lambda) \frac{\left(a-c+\sqrt{e_{k}^{i}}+\sqrt{e_{2}^{j}}\right)^{2}}{9}-\theta_{k} e_{k}^{i} .
$$

The two equilibrium conditions under symmetry can be better expressed in terms of squared efforts:

$$
\begin{aligned}
\sqrt{e_{1}^{*}} & =\frac{a-c+(1-\lambda) \sqrt{e_{2}^{*}}}{9 \theta_{1}-1-\lambda}, \\
\sqrt{e_{1}^{*}} & =\frac{\left(9 \theta_{2}-2+\lambda\right) \sqrt{e_{2}^{*}}-(a-c)}{\lambda},
\end{aligned}
$$

which are linearly increasing relations as those shown in Figure 2 - clearly, the square of these expressions provides the equilibrium relations $e_{1}^{*}=f^{*}\left(e_{2}^{*}, \theta_{1}\right)$ and $e_{1}^{*}=h^{*}\left(e_{2}^{*}, \theta_{2}\right)$ as quadratic expressions satisfying assumption A.2. They cross only once at the following effort levels:

$\sqrt{e_{1}^{*}}=\frac{(a-c)\left(9 \theta_{2}-1\right)}{\left(9 \theta_{2}-2+\lambda\right)\left(9 \theta_{1}-1-\lambda\right)-\lambda(1-\lambda)}>\sqrt{e_{2}^{*}}=\frac{(a-c)\left(9 \theta_{1}-1\right)}{\left(9 \theta_{2}-2+\lambda\right)\left(9 \theta_{1}-1-\lambda\right)-\lambda(1-\lambda)}$,

which are also increasing in the scale of the market $a-c$. 


\subsection{Contract competition with asymmetric information}

In this section we finally move to asymmetric information and make the assumption that managers have private information on their productivity within each hierarchy. One can think of managers as specialists in the differentiated production of each firm, each one with private information on productivity. This is typical of top managers in oligopolistic markets, and allows us to abstract from competition for the managers. ${ }^{8}$

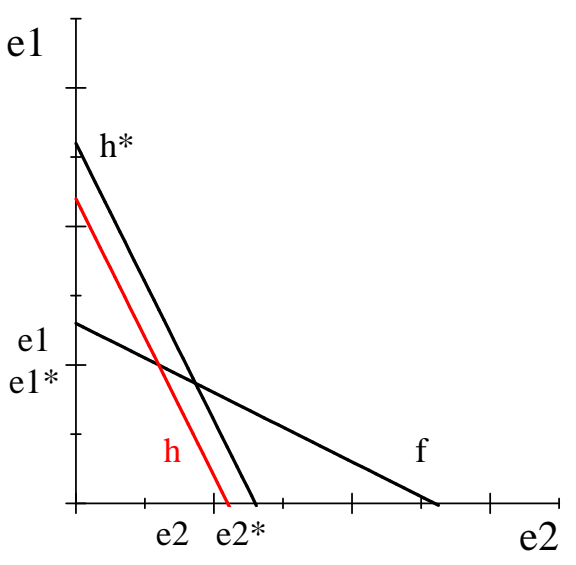

Fig. 1: The case of strategic substitutes

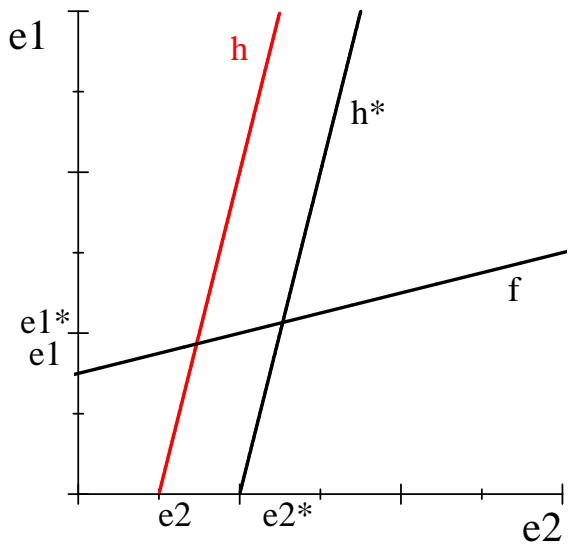

Fig. 2: The case of strategic complements

When offering a contract each principal optimally screens for its own manager's type and takes as given the optimal contractual behavior of the rival firm. ${ }^{9}$ In this case, both elements of a contract (effort and wage) and the allocation of property rights affect directly the surplus created in a hierarchy and, indirectly, in the other hierarchy. Therefore the same allocation of bargaining power between principal and agent within hierachies does affect the equilibrium outcomes. Accordingly, following most of the principal-agent literature, we will now assume that the principal is the firm's ower ${ }^{10}$ and

\footnotetext{
${ }^{8}$ Biglaiser and Mezzetti (2000) have considered auctions to hire managers in a principal-agent framework. With identical principals, the equilibrium gives all the surplus to each type of worker.

${ }^{9}$ As mentioned before we always assume that firm $i$ 's contract cannot be conditioned on the type of the manager of firm $j$ or, more generally, on messages sent from that firm. The literature on competing mechanisms has investigated equilibria of this kind in different frameworks - see, for a survey, Peters (2014).

${ }^{10}$ More efficient solutions to the moral hazard problem could be reached by changing the ownership structure and selling the right to control to the manager. However wealth constraints make this solution often unrealistic (see Lewis and Sappington, 2000, for a general treatment), and we will not consider it here.
} 
can exercise bargaining power with "take-it or leave-it" offers to the manager. ${ }^{11}$

Exploiting the Reveleation Principle for Bayesian implementation (see Myerson, 1982), ${ }^{12}$ the optimal contract of each firm must maximize expected profits over the four possible states of the world subject to both participation and incentive compatibility constraints for its manager and taking as given the contract of the other firm. As before we look for a Bayesian-Nash equilibrium in contracts. The optimization problem for each firm owner $i$ is:

$$
\begin{gathered}
\max _{\left(e_{k}^{i}, w_{k}^{i}\right)_{k=1,2}} E\left(\pi^{i}\right)=\lambda\left[\lambda \Pi\left(e_{1}^{i}, e_{1}^{j}\right)+(1-\lambda) \Pi\left(e_{1}^{i}, e_{2}^{j}\right)-w_{1}^{i}\right] \\
+(1-\lambda)\left[\lambda \Pi\left(e_{2}^{i}, e_{1}^{j}\right)+(1-\lambda) \Pi\left(e_{2}^{i}, e_{2}^{j}\right)-w_{2}^{i}\right] \\
\text { s.t. }: w_{1}^{i} \geq g\left(\theta_{1}, e_{1}^{i}\right) \\
w_{2}^{i} \geq g\left(\theta_{2}, e_{2}^{i}\right) \\
w_{1}^{i}-g\left(\theta_{1}, e_{1}^{i}\right) \geq w_{2}^{i}-g\left(\theta_{1}, e_{2}^{i}\right) \\
w_{2}^{i}-g\left(\theta_{2}, e_{2}^{i}\right) \geq w_{1}^{i}-g\left(\theta_{2}, e_{1}^{i}\right)
\end{gathered}
$$

where $\left(e_{1}^{i}, w_{1}^{i}\right)$ and $\left(e_{2}^{i}, w_{2}^{i}\right)$ are the contracts offered by firm $i$ to its manager of type $\theta_{1}$ and $\theta_{2}$ respectively. The first pair of constraints ensure participation while the second one guarantees truthtelling. Since the contract of the other firm is taken as given, standard arguments imply that the binding constraints are the participation constraint for the inefficient manager and the incentive compatibility constraint for the efficient one. ${ }^{13}$ This allows us to state the individually rational and incentive compatible wages as follows:

$$
\begin{aligned}
& w_{2}^{i}=g\left(\theta_{2}, e_{2}^{i}\right) \\
& w_{1}^{i}=g\left(\theta_{1}, e_{1}^{i}\right)+\Phi\left(e_{2}^{i}, \theta_{1}, \theta_{2}\right),
\end{aligned}
$$

where $\Phi\left(e_{2}^{i}, \theta_{1}, \theta_{2}\right) \equiv g\left(\theta_{2}, e_{2}^{i}\right)-g\left(\theta_{1}, e_{2}^{i}\right)$ is defined as the informational rent, with $\Phi \geq 0, \Phi_{e} \geq 0$ and $\Phi_{e e} \geq 0$ under our assumptions. If we substitute the constraints (22)

\footnotetext{
${ }^{11}$ For an analysis of alternative bargaining solutions in models with moral hazard see Demougin and Helm (2006) and Dittrich and Städter (2015).

${ }^{12}$ As is well known, d'Aspremont and Gerard-Varet (1979) introduced Bayesian implementation. See Ledyard and Palfrey (1999) for a modern treatment on public goods.

${ }^{13}$ We can check later that the solution is monotonic, which guarantees global incentive compatibility. There is no need for a modified monotonicity condition as in Piccolo et al. (2008) because here incentives constraint are not modified by contract competition.
} 
and (23) in the objective function and then take the derivative with respect to $e_{1}^{i}$ and $e_{2}^{i}$, we obtain the following first-order conditions:

$$
\lambda \Pi_{1}\left(e_{1}^{i}, e_{1}^{j}\right)+(1-\lambda) \Pi_{1}\left(e_{1}^{i}, e_{2}^{j}\right)=g_{e}\left(\theta_{1}, e_{1}^{i}\right),
$$

and

$$
\lambda \Pi_{1}\left(e_{2}^{i}, e_{1}^{j}\right)+(1-\lambda) \Pi_{1}\left(e_{2}^{i}, e_{2}^{j}\right)=g_{e}\left(\theta_{2}, e_{2}^{i}\right)+\frac{\lambda}{1-\lambda} \Phi_{e}\left(e_{2}^{i}, \theta_{1}, \theta_{2}\right) .
$$

For given effort levels of the rival firm ( $e_{k}^{j}$ for its two possible types), these conditions can be compared to (16): they provide a standard constrained optimal mechanism for the choice of contracts in the presence of asymmetric information, and they show nodistortion on the top and downward distortion at the bottom. Taking strategic interactions into account, however, introduces deeper differences compared to the benchmark without asymmetric information (17)-(18). Since we are looking for a symmetric equilibrium we set $e_{k}^{i}=e_{k}^{j}=e_{k}$ and obtain:

Proposition 2 Under Assumptions A.1, contract competition with asymmetric information within hierarchies generates effort levels $e_{1}>e_{2}$ such that:

$$
\begin{aligned}
\lambda \Pi_{1}\left(e_{1}, e_{1}\right)+(1-\lambda) \Pi_{1}\left(e_{1}, e_{2}\right) & =g_{e}\left(\theta_{1}, e_{1}\right) \\
\lambda \Pi_{1}\left(e_{2}, e_{1}\right)+(1-\lambda) \Pi_{1}\left(e_{2}, e_{2}\right) & =g_{e}\left(\theta_{2}, e_{2}\right)+\frac{\lambda}{1-\lambda} \Phi_{e}\left(e_{2}, \theta_{1}, \theta_{2}\right)
\end{aligned}
$$

To analyze the equilibrium graphically, we use (24) and (25) as implicitly defining two functions $e_{1} \equiv f\left(e_{2}, \theta_{1}\right)$ and $e_{1} \equiv h\left(e_{2}, \theta_{2}, \theta_{1}\right)$. The former is the same relation emerging under uncertainty, $f\left(e_{2}, \theta_{1}\right)=f^{*}\left(e_{2}, \theta_{1}\right)$, already depicted in Figure 1 and 2 , with slope:

$$
f_{e}\left(e_{2}, \theta_{1}\right)=\frac{(1-\lambda) \Pi_{12}\left(e_{1}, e_{2}\right)}{g_{e e}\left(\theta_{1}, e_{1}\right)-(1-\lambda) \Pi_{11}\left(e_{1}, e_{2}\right)-\lambda\left[\Pi_{11}\left(e_{1}, e_{1}\right)+\Pi_{12}\left(e_{1}, e_{1}\right)\right]} .
$$

The latter is related to the earlier relation, but incorporates an additional factor due to the informational rent. This shifts the $h$ function inward compared to the $h^{*}$ function, as shown in Figures 1 and 2. Moreover, the slope becomes steeper:

$h_{e}\left(e_{2}, \theta_{2}, \theta_{1}\right)=\frac{g_{e e}\left(\theta_{2}, e_{2}\right)+\frac{\lambda}{1-\lambda} \Phi_{e e}\left(e_{2}, \theta_{1}, \theta_{2}\right)-\lambda \Pi_{11}\left(e_{2}, e_{1}\right)-(1-\lambda)\left[\Pi_{11}\left(e_{2}, e_{2}\right)+\Pi_{12}\left(e_{2}, e_{2}\right)\right]}{\lambda \Pi_{12}\left(e_{2}, e_{1}\right)}$.

Our key assumption for the existence of a unique interior equilibrium extends the earlier one as follows: 
A.2.: For any effort $e$ :

$$
\left|h_{e}\left(e_{2}, \theta_{2}, \theta_{1}\right)\right|>\left|f_{e}\left(e_{2}, \theta_{1}\right)\right|
$$

Assumption A.2. implies that under strategic substitutability $h_{e}\left(e_{2}, \theta_{2}, \theta_{1}\right)$ crosses $f\left(e_{2}, \theta_{1}\right)$ once and from above, and under strategic complementarity $h_{e}\left(e_{2}, \theta_{2}, \theta_{1}\right)$ crosses $f\left(e_{2}, \theta_{1}\right)$ once and from below, which is sufficient to guarantee the existence of a unique equilibrium.

The equilibrium conditions show that, as usual, the informational rent "virtually" increases the marginal cost of effort for an inefficient manager. However, the same informational rent creates new consequences on the marginal benefit of effort for an efficient manager. To understand these consequences we compare the effort levels that result in this framework with asymmetric information and those that emerge in the framework with uncertainty of the previous section:

Proposition 3 Under Assumptions A.1-2, under contract competition with asymmetric information within hierarchies, strategic substitutability in contracts implies $e_{1}>e_{1}^{*}$ and $e_{2}<e_{2}^{*}$, and strategic complementarity in contracts implies $e_{1}<e_{1}^{*}$ and $e_{2}<e_{2}^{*}$.

Graphically, it is immediate to verify that, under our assumptions the consequence of asymmetric information is to reduce the effort by inefficient managers always and change the effort of efficient managers in a way that depends on the nature of the strategic relation: when efforts are strategic substitutes, asymmetric information induces higher effort by the efficient managers, but when they are strategic complements, it creates a downward distortion also for the efficient managers.

The intuition for this result relies on uncertainty and on the strategic interaction between contracts. In the presence of asymmetric information, each principal tends to distort downward the effort and the compensation of the inefficient manager. In the absence of strategic interactions between contracts, as in case of isolated hierarchies, each principal would not distort the effort of the efficient manager. However, if there is strategic substitutability between contracts, the reduction in the effort of the inefficient managers increases the expected marginal profitability of effort of the efficient managers, generating the optimality of an upward distortion of their effort levels. This reinforces the need of a downward distortion of the effort of the inefficient managers, and the assumption that guarantees the existence of a unique equilibrium guarantees also that the process converges. To the contrary, if there is strategic complementarity, the lower effort of the inefficient managers reduces the expected marginal profitability of the effort 
of the efficient managers and induces each principal to distort downward that effort as well. Again, this induces a feedback on the inefficient managers, requiring an even lower effort, but the process converges to an equilibrium under our assumptions.

Example 1: Contract competition in $\mathbf{R} \& \mathbf{D}$ Let us return to our example where two firms are engaged in a competition for the market with strategic substitutability in contracts. In this case we have $\Phi(e) \equiv\left(\theta_{2}-\theta_{1}\right) e^{2} / 2$ and the equilibrium under asymmetric information provides:

$$
\begin{aligned}
& e_{1}=\frac{\theta_{2}+\frac{\lambda}{1-\lambda}\left(\theta_{2}-\theta_{1}\right)}{\left(\theta_{1}+\lambda\right)\left[\theta_{2}+\frac{\lambda}{1-\lambda}\left(\theta_{2}-\theta_{1}\right)\right]+(1-\lambda) \theta_{1}}>e_{1}^{*}, \\
& e_{2}=\frac{\theta_{1}}{\left(\theta_{1}+\lambda\right)\left[\theta_{2}+\frac{\lambda}{1-\lambda}\left(\theta_{2}-\theta_{1}\right)\right]+(1-\lambda) \theta_{1}}<e_{2}^{*} .
\end{aligned}
$$

These contracts exhibit polarization of efforts and managerial compensations compared to the case without asymmetric information.

Example 2: Two-stage competition with large spillovers In the example of two-stage competition with strategic complementarity in contracts we can derive the equilibrium effort levels as follows:

$$
\begin{aligned}
& \sqrt{e_{1}}=\frac{(a-c)\left(9 \tilde{\theta}_{2}-1\right)}{\left(9 \tilde{\theta}_{2}-2+\lambda\right)\left(9 \theta_{1}-1-\lambda\right)-\lambda(1-\lambda)}<\sqrt{e_{1}^{*},} \\
& \sqrt{e_{2}}=\frac{(a-c)\left(9 \theta_{1}-1\right)}{\left(9 \tilde{\theta}_{2}-2+\lambda\right)\left(9 \theta_{1}-1-\lambda\right)-\lambda(1-\lambda)}<\sqrt{e_{2}^{*},}
\end{aligned}
$$

where we defined the virtual type $\tilde{\theta}_{2} \equiv \theta_{2}+\frac{\lambda}{1-\lambda}\left(\theta_{2}-\theta_{1}\right)>\theta_{2}$. Efforts are now distorted downward.

It is important to remark that the equilibrium contractual properties of two-stage competition do not depend on the form of competition in the last stage, but from the nature of the interactions between contracts. For instance, when managerial effort exerts small spillovers on the rival and goods are substitutes in the final market, strategic substitutability occurs under both quantity and price competition, which makes this case much more relevant for practical purposes compared to the case of strategic complemen- 
tarity. ${ }^{14}$ To verify this, we will conclude this section presenting a simple example based on price competition in the second stage without spillovers between contracts.

Example 3: Hotelling competition with marketing costs To provide an example with price competition, let us consider a simple model à la Hotelling (1929). Firms are located at both ends of a unit segment and consumers are uniformly distributed along this segment with the indirect utility $U=\max _{i=1,2} a-p_{i}-\left(d_{i}-e^{i}\right)$, where $p_{i}$ is the price charged by producer $i$ for a unit of good and $a$ is the maximum willingness to pay for the good. Moreover, $d_{i}$ is the distance from producer $i=1,2$, and the marketing investment $e^{i}$ reduces the cost of this distance for every consumer. In a first stage each manager chooses the marketing cost. In a second stage, uncertainty is resolved and firms compete in prices. Firm $i$ has demand $D_{i}=\left(1+p_{j}-p_{i}+e^{i}-e^{j}\right) / 2$ and sets prices to maximize its profits:

$$
\pi^{i}=\frac{\left(p_{i}-c\right)\left(1+p_{j}-p_{i}+e^{i}-e^{j}\right)}{2}-w^{i},
$$

taking as given the price choice of the rival and the contracts. The reaction functions are $p_{i}=\left(c+1+e^{i}-e^{j}+p_{j}\right) / 2$, and the equilibrium prices are:

$$
p_{i}=1+c+\frac{e^{i}-e^{j}}{3} .
$$

As usual price competition is characterized by strategic complementarity in prices. However, gross profits exhibit strategic substitutability in the effort levels. Indeed, replacing (30) in (29) we obtain:

$$
\Pi\left(e^{i}, e^{j}\right)=\left(1+\frac{e^{i}-e^{j}}{3}\right)\left(\frac{1+e^{i}-e^{j}}{2}\right)
$$

whose cross derivative is $\Pi_{12}\left(e^{i}, e^{j}\right)=-1 / 3$. As a consequence, a two-way distortion of effort levels emerges under contract competition with asymmetric information.

\section{Imperfectly Correlated Types}

In this section we generalize our model to allow for imperfectly correlated types of managers. Indeed, the limit case of perfect correlation between types of managers is well known in the literature since Martimort (1996). If managers are always hit by the same

\footnotetext{
${ }^{14}$ However, if goods are complements, strategic complementarity between efforts emerges.
} 
shocks, the two hierarchies are virtually independent and the equilibrium contracts under uncertainty correspond to those obtained in (13), and under asymmetric information they are characterized by the classic no-distortion at the top and downward distortion at the bottom, without interdependence. Here we will study the case of imperfect correlation, in which contractual interdependence bites.

Let us assume that the joint prior probability distribution is given as follows:

$$
\begin{array}{cc}
\operatorname{Pr}\left(\theta_{1}, \theta_{1}\right)=\lambda^{2}+\alpha & \operatorname{Pr}\left(\theta_{1}, \theta_{2}\right)=\lambda(1-\lambda)-\alpha \\
\operatorname{Pr}\left(\theta_{2}, \theta_{1}\right)=\lambda(1-\lambda)-\alpha & \operatorname{Pr}\left(\theta_{2}, \theta_{2}\right)=(1-\lambda)^{2}+\alpha
\end{array}
$$

where $\alpha=\operatorname{Pr}\left(\theta_{1}, \theta_{1}\right) \operatorname{Pr}\left(\theta_{2}, \theta_{2}\right)-\operatorname{Pr}\left(\theta_{1}, \theta_{2}\right) \operatorname{Pr}\left(\theta_{2}, \theta_{1}\right)$. The marginal distribution is always given by $\operatorname{Pr}\left(\theta_{1}\right)=\lambda$ and $\operatorname{Pr}\left(\theta_{2}\right)=1-\lambda$. Because of correlation, given the type of manager in a firm, its principal can update the priors on the distribution of the other firm manager's type. The posteriors, computed using Bayes rule $\operatorname{Pr}\left(\theta_{i} \mid \theta_{j}\right)=$ $\operatorname{Pr}\left(\theta_{j} \mid \theta_{i}\right) \operatorname{Pr}\left(\theta_{i}\right) / \operatorname{Pr}\left(\theta_{j}\right)$, are:

$$
\begin{array}{cc}
\operatorname{Pr}\left(\theta_{1} \mid \theta_{1}\right)=\lambda+\frac{\alpha}{\lambda} & \operatorname{Pr}\left(\theta_{1} \mid \theta_{2}\right)=\lambda-\frac{\alpha}{1-\lambda} \\
\operatorname{Pr}\left(\theta_{2} \mid \theta_{1}\right)=1-\lambda-\frac{\alpha}{\lambda} & \operatorname{Pr}\left(\theta_{2} \mid \theta_{2}\right)=1-\lambda+\frac{\alpha}{1-\lambda}
\end{array}
$$

The parameter $\alpha$ is directly related to the correlation of types ex post:

$$
\rho=\operatorname{Pr}\left(\theta_{1} \mid \theta_{1}\right) \operatorname{Pr}\left(\theta_{2} \mid \theta_{2}\right)-\operatorname{Pr}\left(\theta_{1} \mid \theta_{2}\right) \operatorname{Pr}\left(\theta_{2} \mid \theta_{1}\right)=\frac{\alpha}{\lambda(1-\lambda)},
$$

which motivates our focus on the range $\alpha \in[0, \bar{\alpha}]$ where the upper bound $\bar{\alpha}=\lambda(1-\lambda)$ corresponds to the case of perfect correlation.

Consider full information within hierachies and uncertainty across hierarchies. The objective function of a principal that knows the type of its own manager will now depend on that type since the induced posterior probability distribution over the types of the other firm's manager are different. The principal, whose manager is of type $\theta_{k}$, will now maximize expected profits:

$$
\max _{e_{k}^{i}, w_{k}^{i}} E\left(\pi_{k}^{i}\right)=\operatorname{Pr}\left(\theta_{1} \mid \theta_{k}\right) \Pi\left(e_{k}^{i}, e_{1}^{j}\right)+\operatorname{Pr}\left(\theta_{2} \mid \theta_{k}\right) \Pi\left(e_{k}^{i}, e_{2}^{j}\right)-w_{k}^{i},
$$

for $k=1,2$ under individual rationality constraints. Contract competition with full information within hierarchies and uncertainty on the rival type generates effort levels 
$e_{1}^{*}(\alpha)$ and $e_{2}^{*}(\alpha)$ defined by:

$$
\begin{gathered}
\left(\lambda+\frac{\alpha}{\lambda}\right) \Pi_{1}\left(e_{1}^{*}, e_{1}^{*}\right)+\left(1-\lambda-\frac{\alpha}{\lambda}\right) \Pi_{1}\left(e_{1}^{*}, e_{2}^{*}\right)=g_{e}\left(\theta_{1}, e_{1}^{*}\right) \\
\left(\lambda-\frac{\alpha}{1-\lambda}\right) \Pi_{1}\left(e_{2}^{*}, e_{1}^{*}\right)+\left(1-\lambda+\frac{\alpha}{1-\lambda}\right) \Pi_{1}\left(e_{2}^{*}, e_{2}^{*}\right)=g_{e}\left(\theta_{2}, e_{2}^{*}\right) .
\end{gathered}
$$

Clearly, this system implies $e_{1}^{*}(0)=e_{1}^{*}$ and $e_{2}^{*}(0)=e_{2}^{*}$ as defined in Proposition 1, and $e_{1}^{*}(\bar{\alpha})=e_{11}$ and $e_{2}^{*}(\bar{\alpha})=e_{22}$ as defined in Lemma 1 .

When we move to the case of asymmetric information inside each hierarchy, informational rents have to be paid to efficient types. ${ }^{15}$ Each principal chooses contracts to maximize expected profits under the individual rationality constraint for the inefficient manager and the incentive compatibility constraint for the efficient one. The equilibrium conditions for the levels of effort $e_{1}(\alpha)$ and $e_{2}(\alpha)$ can be now derived as:

$$
\begin{gathered}
\left(\lambda+\frac{\alpha}{\lambda}\right) \Pi_{1}\left(e_{1}, e_{1}\right)+\left(1-\lambda-\frac{\alpha}{\lambda}\right) \Pi_{1}\left(e_{1}, e_{2}\right)=g_{e}\left(\theta_{1}, e_{1}\right) \\
\left(\lambda-\frac{\alpha}{1-\lambda}\right) \Pi_{1}\left(e_{2}, e_{1}\right)+\left(1-\lambda+\frac{\alpha}{1-\lambda}\right) \Pi_{1}\left(e_{2}, e_{2}\right)=g_{e}\left(\theta_{2}, e_{2}\right)+\frac{\lambda}{1-\lambda} \Phi_{e}\left(e_{2}, \theta_{1}, \theta_{2}\right) .
\end{gathered}
$$

The system has a unique equilibrium under assumption $A .1-2$ for any $\alpha \in[0, \bar{\alpha}] .{ }^{16}$ This system implies $e_{1}(0)=e_{1}$ and $e_{2}(0)=e_{2}$ as defined in Proposition 2 , and $e_{1}(\bar{\alpha})=e_{11}$ as defined in Lemma 1 with $e_{2}(\bar{\alpha})$ characterized by the same downward distortion that asymmetric information generates within a single firm. For $\alpha \in(0, \bar{\alpha})$ strategic interactions between contracts play a new role and our aim is to verify how correlation affects the equilibrium contracts. The effect of correlation on contract competition depends on whether the principal's profit function exhibits strategic substitutability or complementarity.

\subsection{Strategic substitutability}

The following proposition summarizes the results for the case of strategic substitutability:

Proposition 4 Under Assumptions A.1-2 and strategic substitutability, contract compe-

\footnotetext{
${ }^{15}$ Again, we exclude the possibility of conditioning contracts on messages from the other manager. As is well known since Cremer and McLean (1985), this would allow principals to exploit correlation in a more efficient way - see Bertoletti and Poletti (1997) and Laffont and Martimort (2000) for related applications. However, in our context, contracts based on effort of other managers do not appear realistic.

${ }^{16}$ The generalized slopes $h_{e}\left(e_{2}, \theta_{2}, \theta_{1}, \alpha\right)$ and $f_{e}\left(e_{2}, \theta_{1}, \alpha\right)$ satisfy $\left|h_{e}\left(e_{2}, \theta_{2}, \theta_{1}, \alpha\right)\right|>\left|f_{e}\left(e_{2}, \theta_{1}, \alpha\right)\right|$. Notice that $f_{e}\left(e_{2}, \theta_{1}, \bar{\alpha}\right)=0$ and $h_{e}\left(e_{2}, \theta_{2}, \theta_{1}, \bar{\alpha}\right) \rightarrow \infty$.
} 
tition with asymmetric information on imperfectly correlated types implies that the effort of the efficient manager decreases and the effort of the inefficient manager increases with the degree of correlation, so that differentials in managerial compensation decrease.

Once again we can use our graphical apparatus to interpret this result. In front of an increase in correlation of types the efficient manager puts more weight on the state of the world in which competition occurs with an efficient rival, which reduces its marginal profitability of effort and shifts inward the relation $f$ in Figure 1. At the same time, the inefficient manager puts more weight on the state of the world in which there will be competition with an inefficient rival, which increases its marginal profitability of effort and shifts outward the relation $h$ in Figure 1. This unambiguously increases effort by the inefficient manager and decreases effort by the efficient manager.

The mechanism at work is crucial here: an increase in the correlation of the shocks faced by firms reduces the wage differentials between efficient and inefficient managers because it reduces the comparative advantage of the most productive managers in exerting higher effort. High performance is now perceived as due to positive common circumstances rather than manager specific merits, and the equilibrium contracts reduce the differentiation between managers. Accordingly, markets characterized by higher variability in managers' abilities and lower importance of aggregate shocks in affecting profitability will be characterized by higher wage differentials, which is the main empirical prediction of this theoretical framework.

Example 1: Contract competition in R\&D Let us go back for the last time to our initial example of competition in contracts for the conquest of a new market. With imperfect correlation, the equilibrium in contracts provides:

$$
\begin{aligned}
e_{1}(\alpha) & =\frac{\tilde{\theta}_{2}+\frac{\alpha}{\lambda(1-\lambda)}}{\left(\theta_{1}+\lambda+\frac{\alpha}{\lambda}\right) \tilde{\theta}_{2}+\theta_{1}\left[1-\lambda+\frac{\alpha}{1-\lambda}\right]+\frac{\alpha}{\lambda(1-\lambda)}} \\
e_{2}(\alpha) & =\frac{\theta_{1}+\frac{\alpha}{\lambda(1-\lambda)}}{\left(\theta_{1}+\lambda+\frac{\alpha}{\lambda}\right) \tilde{\theta}_{2}+\theta_{1}\left[1-\lambda+\frac{\alpha}{1-\lambda}\right]+\frac{\alpha}{\lambda(1-\lambda)}}
\end{aligned}
$$


where $e_{1}(\bar{\alpha})=1 /\left(\theta_{1}+1\right)$ and $e_{2}(\bar{\alpha})=1 /\left(\tilde{\theta}_{2}+1\right)$. Labeling $\Delta(\alpha)$ the denominator of the effort levels, we can obtain easily the following comparative statics:

$$
\begin{aligned}
e_{1}^{\prime}(\alpha) & =\frac{\theta_{1} \tilde{\theta}_{2}-\left(\tilde{\theta}_{2}-\theta_{1}\right)-\tilde{\theta}_{2}^{2}}{\lambda \Delta(\alpha)^{2}}<0, \\
e_{2}^{\prime}(\alpha) & =\frac{\theta_{1} \tilde{\theta}_{2}+\left(\tilde{\theta}_{2}-\theta_{1}\right)-\theta_{1}^{2}}{\lambda \Delta(\alpha)^{2}}>0,
\end{aligned}
$$

which confirms that contract polarization increases when $\alpha$ decreases. Most of all, the equilibrium wage differential between efficient and inefficient agents is:

$$
\frac{w_{1}}{w_{2}}=1+\frac{\theta_{1}}{\theta_{2}}\left\{\left[\frac{\tilde{\theta}_{2}+\frac{\alpha}{\lambda(1-\lambda)}}{\theta_{1}+\frac{\alpha}{\lambda(1-\lambda)}}\right]^{2}-1\right\}
$$

which is always decreasing in $\alpha$ and in the correlation index $\rho=\alpha / \lambda(1-\lambda)$. Under strategic substitutability in contracts, the gap between managerial compensations is higher when the correlation of managerial talent is low, or when firms are hit by independent shocks.

\subsection{Strategic complementarity}

The case of strategic complementarity does not provide immediate results of comparative statics. In Figure 2, an increase in correlation of types shifts upward the relation $f$, which would push for an increase in effort of both types, but it also shifts upward the relation $h$, which operates in the opposite direction. Nevertheless we can unambiguously determine what happens at the two extreme cases of zero and perfect correlation:

Proposition 5 Under Assumptions A.1-2 and strategic complementarity, contract competition with asymmetric information on imperfectly correlated types implies that the effort of the efficient manager increases and the effort of the inefficient manager decreases when moving from zero to perfect correlation, so that differentials in managerial compensation increase.

This suggests that over some range an increase in $\alpha$ leads to higher effort by the efficient managers and lower effort by the inefficient ones. An increase in the correlation of the shocks faced by firms tends to increase the wage differentials between efficient and inefficient managers: indeed, when the correlation increases, the high performance 
of a manager is perceived as due to positive common circumstances, which can be better exploited by the most efficient managers compared to the least efficient managers.

Example 2: Two-stage competition with large spillovers In the example of two-stage competition we can derive the equilibrium effort levels as follows:

$$
\begin{aligned}
\sqrt{e_{1}(\alpha)} & =\frac{(a-c)\left(9 \tilde{\theta}_{2}-1-\frac{\alpha}{\lambda(1-\lambda)}\right)}{\left(9 \tilde{\theta}_{2}-2+\lambda-\frac{\alpha}{1-\lambda}\right)\left(9 \theta_{1}-1-\lambda-\frac{\alpha}{\lambda}\right)-\left(\lambda-\frac{\alpha}{1-\lambda}\right)\left(1-\lambda-\frac{\alpha}{\lambda}\right)} \\
\sqrt{e_{2}(\alpha)} & =\frac{(a-c)\left(9 \theta_{1}-1-\frac{\alpha}{\lambda(1-\lambda)}\right)}{\left(9 \tilde{\theta}_{2}-2+\lambda-\frac{\alpha}{1-\lambda}\right)\left(9 \theta_{1}-1-\lambda-\frac{\alpha}{\lambda}\right)-\left(\lambda-\frac{\alpha}{1-\lambda}\right)\left(1-\lambda-\frac{\alpha}{\lambda}\right)}
\end{aligned}
$$

Notice that

$$
e_{1}(\bar{\alpha})=\left(\frac{a-c}{9 \theta_{1}-2}\right)^{2}>e_{1}(0) \quad \text { and } \quad e_{2}(\bar{\alpha})=\left(\frac{a-c}{9 \tilde{\theta}_{2}-2}\right)^{2}<e_{2}(0),
$$

and it can be also verified that $e_{1}^{\prime}(\alpha)>0$ and $e_{2}^{\prime}(\alpha)<0$ for any $\alpha$. The equilibrium wage differential between efficient and inefficient agents is now:

$$
\frac{w_{1}}{w_{2}}=1+\frac{\theta_{1}}{\theta_{2}}\left\{\left[\frac{9 \tilde{\theta}_{2}-1-\frac{\alpha}{\lambda(1-\lambda)}}{9 \theta_{1}-1-\frac{\alpha}{\lambda(1-\lambda)}}\right]^{2}-1\right\}
$$

which is always increasing in $\alpha$ and $\rho=\alpha / \lambda(1-\lambda)$ : under strategic complementarity in contracts, managerial compensations diverge when firms are hit by more similar shocks.

\subsection{Commitments, entry and empirical predictions}

When contracts are strategic substitutes, each firm has an incentive to adopt aggressive contracts which require an efficient manager to overinvest in effort and an inefficient contract to underinvest. This leads to a duopolistic equilibrium where firms are aggressive and would gain from reducing their investments, a typical result of strategic games. As we have argued, this is the natural outcome of models with $R \& D$ investments or with two stage competition between firms producing substitute goods and competing either in quantities or prices as long as the spillovers between contracts are limited.

The case of strategic complementarity induces firms to behave in an accommodating way, reducing the effort required from both efficient and inefficient managers. This softening of competition through contracts allows firms to increase their profits. How- 
ever, this case appears only as a theoretical possibility for two reasons. First, it requires extremely large spillovers between contracts (or goods complementarity), independently from the form of the final competition in the market. Second, as well known from the theory of endogenous market structures (see Etro, 2011,and Bertoletti and Etro, 2016), accommodating strategies tend to increase profits in the short run but also to attract entry in the long run. Taking endogenous entry into account, each firm would have an incentive to behave in an aggressive way independently from whether strategic substitutability or complementarity holds.

The extension of our analysis to oligopoly and endogenous entry has been analyzed in Etro and Cella (2013), showing that an increase in the number of firms increases the compensation differentials between (any) two types of managers, which suggests a first empirical prediction: a positive relation between competition and high-powered incentives. Here we have seen that a reduction in the correlation of shocks increases the compensation differentials, which suggests a second empirical prediction: a negative relation between covariance of industry shocks and high-powered incentives.

\section{Conclusion}

In this work we have analyzed the choice of incentive contracts by competing hierarchies. Asymmetric information on imperfectly correlated shocks creates a two-way distortion of efforts in markets where there is strategic substitutability, which is typical of markets with both quantity and price competition and investments in $R \& D$ or demand enhancing activities with small spillovers. In this case a lower correlation of managerial talent or shocks to profitability increases the polarization of contracts and the compensation differential between managers.

Further investigations may study the welfare impact of contract competition and analyze more complex forms of this form of competition, such as competition with more complex contracts based on profits or contracts of the rivals (relative performance evaluation) or competition between a private firm and a regulated firm. ${ }^{17}$

\section{References}

[1] Aggarwal, R. K. and A. A. Samwick (1999,a) "The Other Side of the Trade-off: The Impact of Risk on Executive Compensation", Journal of Political Economy, 107, 1,

\footnotetext{
${ }^{17}$ See Peters (2014) on competing mechanisms and the classic work by Laffont and Tirole (1993) and the recent one by Calzolari and Scarpa (2012) on regulated firms with asymmetric information.
} 
$65-105$

[2] Aggarwal, R. K. and A. A. Samwick (1999,b) "Executive Compensation, Strategic Competition, and Relative Performance Evaluation: Theory and Evidence", Journal of Finance, 54, 6, 1999-2043

[3] Baggs, J. and J.-E. de Bettignies (2007) "Product Market Competition an Agency Costs", Journal of Industrial Economics, 55, 2, 289-323

[4] Baron, D. and R. Myerson (1982) "Regulating a Monopolist with Unknown Costs", Econometrica, 50, 4, 911-930

[5] Bertoletti, P. and F. Etro (2016) "Preferences, Entry and Market Structure", RAND Journal of Economics, in press

[6] Bertoletti, P. and C. Poletti (1997) "X-Inefficiency, Competition and Market Information", Journal of Industrial Economics, 45, 4, 359-75

[7] Biglaiser G. and C. Mezzetti (2000) "Incentive Auctions and Information Revelation", RAND Journal of Economics, 31, 1, 145-64

[8] Brainard, S.L. and D. Martimort (1996) "Strategic Trade Policy Design with Asymmetric Information and Public Contracts", Review of Economic Studies, 63, 81-105

[9] Calzolari, G. and C. Scarpa (2012) "On Regulation and Competition: Pros and Cons of a Diversified Monopolist", WP 55, Fondazione Eni Enrico Mattei

[10] Crémer, J. and R. P. McLean (1985) "Optimal Selling Strategies under Uncertainty for a Discriminating Monopolist when Demands are Interdependent", Econometrica, $53,2,345-61$

[11] d'Aspremont, C. and C. Gerard-Varet (1979) "Incentives and Incomplete Information", Journal of Public Economics, 11, 1, 25-45

[12] Demougin, D. and C. Helm (2006) "Moral Hazard and Bargaining Power", German Economic Review, 7, 4, 463-70

[13] Dittrich, M. and M Städter (2015) "Moral Hazard and Bargaining over Incentive Contracts", Research in Economics, 69, 1, 75-85

[14] Etro, F. (2011) "Endogenous Market Structures and Contract Theory: Delegation, Principal-Agent Contracts, Screening, Franchising and Tying", European Economic Review, 55, 4, 463-79 
[15] Etro, F. and M. Cella (2013) "Equilibrium Principal-Agent Contracts: Competition and R\&D Incentives", Journal of Economic \& Management Strategy, 22, 3, 488-512

[16] Gabaix, X. and A. Landier (2008) "Why has CEO pay Increased so Much?", Quarterly Journal of Economics, 123, 49-100

[17] Hotelling, H. (1929) "Stability in Competition", Economic Journal, 39, 41-57

[18] Jensen, M. and K. Murphy (1990) "Performance Pay and Top-Management Incentives", Journal of Political Economy, 98, 2, 225-64

[19] Karuna, C. (2007) "Industry Product Market Competition and Managerial Incentives", Journal of Accounting and Economics, 43, 2-3, 275-97

[20] Laffont, J.-J. and D. Martimort (2000) "Mechanism Design with Collusion and Correlation", Econometrica, 68, 2, 309-42

[21] Laffont, J.-J. and J. Tirole (1993) A Theory of Incentives in Procurement and Regulation, The MIT Press

[22] Laffont, J.-J. and J. Tirole (1986) "Using Cost Observation to Regulate Firms", Journal of Political Economy, 94, 3, 614-41

[23] Lazear, (2015) "The Impatient Salesperson and the Delegation of Pricing Authority", Research in Economics, 69, 1, 63-74

[24] Ledyard, J. and T. R. Palfrey (1999) "A Characterization of Interim Efficiency with Public Goods", Econometrica, 67, 2, 435-48

[25] Lewis , T.R. and D.E.M. Sappington (1989) "Countervailing Incentives in Agency Problems", Journal of Economic Theory, 49, 2, 294-313

[26] Lewis, T.R. and D.E.M. Sappington (2000) "Motivating Wealth-Constrained Actors", American Economic Review, 90, 4, 944-60

[27] Martimort, D. (1996) "Exclusive Dealing, Common Agency, and Multiprincipal Incentive Theory", RAND Journal of Economics, 27, 1, 1-31

[28] Murphy, K. J. (1999) "Executive Compensation", in Handbook of Labor Economics, O. Ashenfelter and D. Card Eds, Ch. 38, 2485-563, Elsevier

[29] Myerson, R. B. (1982) "Optimal Coordination Mechanisms in Generalized Principal-Agent Problems", Journal of Mathematical Economics, 10, 1, 67-81 
[30] Peters, M. (2014) "Competing Mechanisms," Canadian Journal of Economics, 47, 2, 373-97

[31] Piccolo, S., M. D'Amato and R. Martina (2008) "Product Market Competition and Organizational Slack under Profit-target Contracts", International Journal of Industrial Organization, 26, 1389-406

[32] Piccolo, S. and M. Pagnozzi (2013) "Information Sharing between Vertical Hierarchies", Games and Economic Behavior, 79, 201-22

[33] Rosen, S. (1981) "The Economics of Superstars", American Economic Review, 71, $5,845-58$

\section{Appendix}

Proof of Proposition 1. To prove $e_{1}^{*} \geq e_{2}^{*}$ assume, by contradiction, that the opposite holds, that is $e_{1}^{*}<e_{2}^{*}{ }^{18}$ Then, since $g_{e \theta}>0$ and $g_{e e \theta} \geq 0$ by $A .1$., it must be that:

$$
g_{e}\left(\theta_{1}, e_{1}^{*}\right)<g_{e}\left(\theta_{2}, e_{1}^{*}\right) \leq g_{e}\left(\theta_{2}, e_{2}^{*}\right)
$$

Moreover, since $\Pi_{11} \leq 0$, it must be that:

$$
\begin{aligned}
g_{e}\left(\theta_{1}, e_{1}^{*}\right) & =\lambda \Pi_{1}\left(e_{1}^{*}, e_{1}^{*}\right)+(1-\lambda) \Pi_{1}\left(e_{1}^{*}, e_{2}^{*}\right) \\
& \geq \lambda \Pi_{1}\left(e_{2}^{*}, e_{1}^{*}\right)+(1-\lambda) \Pi_{1}\left(e_{2}^{*}, e_{2}^{*}\right)=g_{e}\left(\theta_{2}, e_{2}^{*}\right)
\end{aligned}
$$

which contradicts the previous inequality.

Proof of Proposition 2. To prove $e_{1} \geq e_{2}$ assume, by contradiction, that the opposite holds, that is $e_{1}<e_{2}$. Then, since $g_{e \theta}>0$ and $g_{e e \theta} \geq 0$ by $A .1$, it must be that:

$$
g_{e}\left(\theta_{1}, e_{1}\right)<g_{e}\left(\theta_{2}, e_{1}\right) \leq g_{e}\left(\theta_{2}, e_{2}\right)
$$

which implies:

$$
g_{e}\left(\theta_{1}, e_{1}\right)<g_{e}\left(\theta_{2}, e_{2}\right)+\frac{\lambda}{1-\lambda} \Phi_{e}\left(e_{2}, \theta_{1}, \theta_{2}\right)
$$

Moreover, since $\Pi_{11} \leq 0$, it must be that:

$$
\begin{aligned}
g_{e}\left(\theta_{1}, e_{1}\right) & =\lambda \Pi_{1}\left(e_{1}, e_{1}\right)+(1-\lambda) \Pi_{1}\left(e_{1}, e_{2}\right) \\
& \geq \lambda \Pi_{1}\left(e_{2}, e_{1}\right)+(1-\lambda) \Pi_{1}\left(e_{2}, e_{2}\right)=g_{e}\left(\theta_{2}, e_{2}\right)+\frac{\lambda}{1-\lambda} \Phi_{e}\left(e_{2}, \theta_{1}, \theta_{2}\right)
\end{aligned}
$$

\footnotetext{
${ }^{18}$ We are grateful to an anonymous referee for suggesting the proofs by contradiction.
} 
which contradicts the previous inequality.

Proof of Proposition 3. Let us consider the following system:

$$
\begin{aligned}
& F\left(e_{1}, e_{2}\right) \equiv \lambda \Pi_{1}\left(e_{1}, e_{1}\right)+(1-\lambda) \Pi_{1}\left(e_{1}, e_{2}\right)-g_{e}\left(\theta_{1}, e_{1}\right)=0 \\
& H\left(e_{1}, e_{2}\right) \equiv \lambda \Pi_{1}\left(e_{2}, e_{1}\right)+(1-\lambda) \Pi_{1}\left(e_{2}, e_{2}\right)-g_{e}\left(\theta_{2}, e_{2}\right)-\frac{\lambda \mu \Phi_{e}\left(e_{2}, \theta_{1}, \theta_{2}\right)}{1-\lambda}=0
\end{aligned}
$$

which defines $\left(e_{1}^{*}, e_{2}^{*}\right)$ if $\mu=0$ and $\left(e_{1}, e_{2}\right)$ if $\mu=1$. Applying the Cramer rule we have:

$$
\frac{d e_{1}}{d \mu}=\frac{\frac{\partial F}{\partial e_{2}} \frac{\partial H}{\partial \mu}-\frac{\partial F}{\partial \mu} \frac{\partial H}{\partial e_{2}}}{\Delta}=\frac{-\lambda \Phi_{e}\left(e_{2}, \theta_{1}, \theta_{2}\right) \Pi_{12}\left(e_{1}, e_{2}\right)}{\Delta}
$$

where

$$
\begin{gathered}
\Delta \equiv \frac{\partial F}{\partial e_{1}} \frac{\partial H}{\partial e_{2}}-\frac{\partial F}{\partial e_{2}} \frac{\partial H}{\partial e_{1}}=\frac{\partial F}{\partial e_{1}} \frac{\partial H}{\partial e_{1}}\left[f_{e}(e, \theta)-h_{e}\left(e_{2}, \theta_{2}, \theta_{1}\right)\right] \\
\frac{\partial F}{\partial e_{1}}=\lambda \Pi_{11}\left(e_{1}, e_{1}\right)+\lambda \Pi_{12}\left(e_{1}, e_{1}\right)+(1-\lambda) \Pi_{11}\left(e_{1}, e_{2}\right)-g_{e e}\left(\theta_{1}, e_{1}\right)<0 \\
\frac{\partial H}{\partial e_{2}}=\lambda \Pi_{11}\left(e_{2}, e_{1}\right)+(1-\lambda) \Pi_{11}\left(e_{2}, e_{2}\right)+(1-\lambda) \Pi_{12}\left(e_{2}, e_{2}\right) \\
-g_{e e}\left(\theta_{2}, e_{2}\right)-\frac{\lambda \Phi_{e e}\left(e_{2}, \theta_{1}, \theta_{2}\right)}{1-\lambda}<0 \\
\frac{\partial F}{\partial e_{2}}=(1-\lambda) \Pi_{12}\left(e_{1}, e_{2}\right) \lessgtr 0 \text { if } \Pi_{12} \lessgtr 0 \\
\frac{\partial H}{\partial e_{1}}=\lambda \Pi_{12}\left(e_{2}, e_{1}\right) \lessgtr 0 \text { if } \Pi_{12} \lessgtr 0
\end{gathered}
$$

Notice that for any $\theta_{2}>\theta_{1}$ we have $\Phi_{e}\left(e_{2}, \theta_{1}, \theta_{2}\right)>0$ by $A .1$ and $\Delta>0$ by $A .2$, therefore:

$$
\frac{d e_{1}}{d \mu} \gtrless 0 \quad \text { if } \quad \Pi_{12} \lessgtr 0 .
$$

Analogously, we have:

$$
\frac{d e_{2}}{d \mu}=\frac{\frac{\partial H}{\partial e_{1}} \frac{\partial F}{\partial \mu}-\frac{\partial H}{\partial \mu} \frac{\partial F}{\partial e_{1}}}{\Delta}=\frac{\lambda \Phi_{e}\left(e_{2}, \theta_{1}, \theta_{2}\right) \frac{\partial F}{\partial e_{1}}}{(1-\lambda) \Delta}<0
$$

Then, the introduction of asymmetric information with $\Phi_{e}>0$ implies $e_{1}>e_{1}^{*}$ and $e_{2}<e_{2}^{*}$ (the two-way distortion) under strategic substitutability, and $\left(e_{1}, e_{2}\right)<\left(e_{1}, e_{2}^{*}\right)$ (double downward distortion) under strategic complementarity.

Proof of Proposition 4. To characterize the comparative statics of the equilib- 
rium effort levels $\left(e_{1}, e_{2}\right)$ with respect to $\alpha$ when $\Pi_{12}\left(e_{1}, e_{2}\right)<0$ we totally differentiate the equilibrium system:

$$
\begin{gathered}
F\left(e_{1}, e_{2}, \alpha\right) \equiv\left(\lambda+\frac{\alpha}{\lambda}\right) \Pi_{1}\left(e_{1}, e_{1}\right)+\left(1-\lambda-\frac{\alpha}{\lambda}\right) \Pi_{1}\left(e_{1}, e_{2}\right)-g_{e}\left(\theta_{1}, e_{1}\right)=0, \\
H\left(e_{1}, e_{2}, \alpha\right) \equiv\left(\lambda-\frac{\alpha}{1-\lambda}\right) \Pi_{1}\left(e_{2}, e_{1}\right)+\left(1-\lambda+\frac{\alpha}{1-\lambda}\right) \Pi_{1}\left(e_{2}, e_{2}\right) \\
-g_{e}\left(\theta_{2}, e_{2}\right)-\frac{\lambda \Phi_{e}\left(e_{2}, \theta_{1}, \theta_{2}\right)}{1-\lambda}=0
\end{gathered}
$$

and apply the Cramer rule as before to obtain:

$$
\frac{d e_{1}}{d \alpha}=\frac{\frac{\partial F}{\partial e_{2}} \frac{\partial H}{\partial \alpha}-\frac{\partial F}{\partial \alpha} \frac{\partial H}{\partial e_{2}}}{\Delta}<0
$$

where again $\Delta>0$ by $A .2$. Under strategic substitutability we have:

$$
\begin{aligned}
& \frac{\partial F}{\partial e_{2}}=\left(1-\lambda-\frac{\alpha}{\lambda}\right) \Pi_{12}\left(e_{1}, e_{2}\right)<0, \\
& \frac{\partial H}{\partial \alpha}=\frac{\Pi_{1}\left(e_{2}, e_{2}\right)-\Pi_{1}\left(e_{2}, e_{1}\right)}{1-\lambda}>0, \\
& \frac{\partial F}{\partial \alpha}=\frac{\Pi_{1}\left(e_{1}, e_{1}\right)-\Pi_{1}\left(e_{1}, e_{2}\right)}{\lambda}<0, \\
& \frac{\partial H}{\partial e_{2}}=\left(\lambda-\frac{\alpha}{1-\lambda}\right) \Pi_{11}\left(e_{2}, e_{1}\right)+ \\
&\left(1-\lambda+\frac{\alpha}{1-\lambda}\right)\left[\Pi_{11}\left(e_{2}, e_{2}\right)+\Pi_{12}\left(e_{2}, e_{2}\right)\right]-g_{e e}\left(\theta_{2}, e_{2}\right)-\frac{\lambda \Phi_{e e}\left(e_{2}, \theta_{1}, \theta_{2}\right)}{1-\lambda}<0
\end{aligned}
$$

because $\Pi_{1}\left(e_{1}, e_{2}\right)>\Pi_{1}\left(e_{1}, e_{1}\right)$ and $\Pi_{1}\left(e_{2}, e_{2}\right)>\Pi_{1}\left(e_{2}, e_{1}\right)$. Analogously we have $d e_{2} / d \alpha>0$.

Proof of Proposition 5. To compare extreme effort levels under the assumption $\Pi_{12}\left(e_{1}, e_{2}\right)>0$, let us consider the effort of the efficient manager first. Notice that $e_{1}(0)=e_{1}$ as defined in $(24)$ :

$$
\lambda \Pi_{1}\left(e_{1}, e_{1}\right)+(1-\lambda) \Pi_{1}\left(e_{1}, e_{2}\right)=g_{e}\left(\theta_{1}, e_{1}\right),
$$

and $e_{1}(\bar{\alpha})=e_{11}$ as defined in $(13)$ :

$$
\Pi_{1}\left(e_{11}, e_{11}\right)=g_{e}\left(\theta_{1}, e_{11}\right)
$$


Strategic complementarity and $e_{1}>e_{2}$ imply $\Pi_{1}\left(e_{1}, e_{1}\right)>\Pi_{1}\left(e_{1}, e_{2}\right)$ and therefore $e_{1}(\bar{\alpha})=e_{11}>e_{1}(0)=e_{1}$.

Consider the effort of the inefficient manager now. Notice that $e_{2}(0)=e_{2}$ as defined in (25):

$$
\lambda \Pi_{1}\left(e_{2}, e_{1}\right)+(1-\lambda) \Pi_{1}\left(e_{2}, e_{2}\right)=g_{e}\left(\theta_{2}, e_{2}\right)+\frac{\lambda}{1-\lambda} \Phi_{e}\left(e_{2}, \theta_{1}, \theta_{2}\right),
$$

while $e_{2}(\bar{\alpha})$ must satisfy:

$$
\Pi_{1}\left(e_{2}(\bar{\alpha}), e_{2}(\bar{\alpha})\right)=g_{e}\left(\theta_{2}, e_{2}(\bar{\alpha})\right)+\frac{\lambda}{1-\lambda} \Phi_{e}\left(e_{2}(\bar{\alpha}), \theta_{1}, \theta_{2}\right) .
$$

For any $e_{1}>e_{2}$ strategic complementarity implies $\Pi_{1}\left(e_{2}, e_{1}\right)>\Pi_{1}\left(e_{2}, e_{2}\right)$, therefore $e_{2}=e_{2}(0)>e_{2}(\bar{\alpha})$. 